\title{
ENTREVISTA: EDUARDO KREMPSER
}

\author{
INTERVIEW: EDUARDO KREMPSER
}

Paulo Martin Souto Maior ${ }^{1}$

pmsmaior@yahoo.com /https://orcid.org/0000-0003-1701-855X

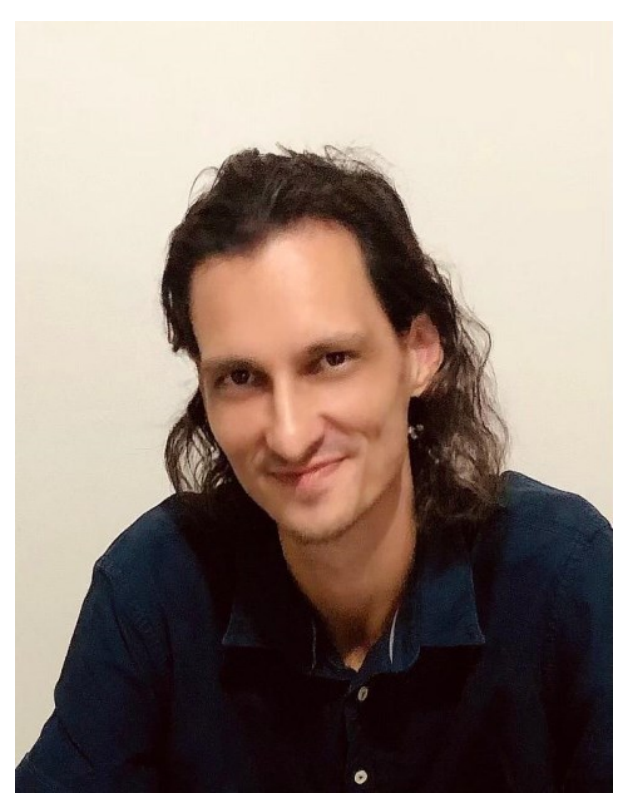

Eduardo Krempser é pesquisador na Fundação Oswaldo Cruz, Fiocruz, no Rio de Janeiro. Graduado em Ciência da Computação pela Universidade Federal de Juiz de Fora em 2007, dedicou-se no mestrado, concluído em 2009, e no doutorado, concluído em 2014, a pesquisa em modelagem computacional no Laboratório Nacional de Computação Científica, LNCC. Entre suas principais pesquisas destacam-se aprendizagem de máquina e a Otimização via Meta-heurísticas. Vem desenvolvendo ferramentas computacionais para modelagem de oportunidades ecológicas para ocorrência de doenças, modelagem molecular, engenharia estrutural, robótica e arqueologia. É membro do Laboratório de Sistemas Inteligentes e Robótica da Faculdade de Educação Tecnológica do Estado do Rio de Janeiro SIRLab/Faeterj, e do Instituto Nacional de Arqueologia, Paleontologia e Ambiente do Semiárido, INCT/CNPq - Inapas.

\footnotetext{
${ }^{1}$ Departamento de Arqueologia, UFPE.
} 
Clio: As informações e a comunicação no mundo hoje são cada vez mais virtuais. A pandemia do Covid-19 veio como uma espécie de fermento nessa forma de se relacionar. Especificamente como isso impactou na arqueologia?

Eduardo Krempser: Informação sempre foi um elemento essencial em todo o processo de tomada de decisão. É natural que o crescimento das tecnologias digitais e da capacidade computacional leve ao incremento da obtenção, disponibilização e tratamento de informações. As áreas do conhecimento não podem se afastar dessa tendência, para tanto, devem-se valer de novas tecnologias que melhorem seus

encontraram nas novas tecnologias de informação e gestão de dados formas de compensar $e$ dinamizar a situação atual planejamentos e suportem o crescimento das informações gerenciadas, inclusive a capacidade interpretativa e de análise dessas informações. Isso deixa claro que o crescimento da capacidade tecnológica também gera aumento da demanda por informações.

O cenário de isolamento social atual, provocado pela pandemia de Covid-19, ressaltou as necessidades de soluções tecnológicas que aproximem pessoas, setores da sociedade e atividades de trabalho de forma virtual, consequentemente, reforçou a demanda pela digitalização e disponibilização de informações. As atividades de pesquisa foram igualmente afetadas e encontraram nas novas tecnologias de informação e gestão de dados formas de compensar e dinamizar a situação atual.

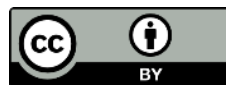


Essa situação não é diferente na arqueologia. O registro e a guarda de dados sempre foi uma preocupação dentro dessa área, que vem utilizando desde sua origem os melhores mecanismos de registros disponíveis. Porém, os aperfeiçoamentos tecnológicos atuais implicam em uma coleta de dados cada vez mais precisa e melhor representada, que permitem análises mais acuradas e futuras avaliações por

os aperfeiçoamentos tecnológicos atuais implicam em uma coleta de dados cada vez, mais precisa $e$ melhor representada diferentes

pesquisadores. maior e mais complexo de informações que devem ser gerenciadas.

Acredito que a demanda por essas informações e o crescimento computacional, bem como o uso de novas tecnologias, deva ser internalizada em todas as etapas da pesquisa arqueológica, desde o seu planejamento até sua divulgação. Não se trata mais de ver a computação como uma atividade em que o pesquisador irá digitalizar um resultado, mas sim, que a computação deva ser um suporte para todas as atividades que possam ser realizadas neste processo de pesquisa, em especial para a arqueologia, sendo ela uma disciplina intrinsicamente interdisciplinar, no qual várias áreas do conhecimento apoiam desde a gerência do dado de origem até novas formas de análise.

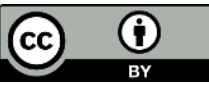


Clio: O Senhor vem trabalhando em um sistema de coleta, gestão e divulgação de conteúdo arqueológico. Em que consiste?

Eduardo Krempser: Sou um dos pesquisadores vinculados ao $\mathrm{INCT}^{2}$ Inapas. É uma rede formada por quatro instituições ${ }^{3}$ e que desenvolvem pesquisas nas áreas de arqueologia, paleoambiente, paleoparasitologia e paleontologia no Semiárido. O Inapas tem como objetivo caracterizar e definir cronologicamente a ocupação préhistórica da região Nordeste do Brasil e a ideia é integrar e usar novas metodologias da pesquisa arqueológica e paleoambiental.

Eu no Inapas atuo como cientista da computação na análise de dados arqueológicos e nas suas relações contextuais e aplico métodos de Aprendizagem de Máquina que é uma subárea de inteligência artificial. Acontece que nesse contexto de interação entre a ciência da computação e a arqueologia foram identificadas oportunidades de gerenciamento e disponibilização de informações arqueológicas. Para implementar essas oportunidades foi desenvolvida uma plataforma computacional, disponível de forma on-line $e^{4}$, com o objetivo de atender demandas tanto da pesquisa científica quanto da arqueologia preventiva.

\footnotetext{
${ }^{2}$ Institutos Nacionais de Ciência e Tecnologia/CNPq. Instituto Nacional de Arqueologia, Paleontologia e Ambiente do Semiárido do Nordeste, INCT/CNPq - Inapas.

${ }^{3}$ Fumdham, UFPE, Fiocruz e Urca.

${ }^{4} \mathrm{http}$ ://summa.fumdham.org.br
}

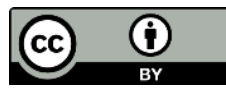




\section{Clio Arqueológica: Qual o nome e como funciona essa plataforma?}

Eduardo Krempser: Se chama Plataforma Capivara e é um conjunto de soluções tecnológicas para o gerenciamento do grande volume de informações provenientes de trabalhos arqueológicos e paleontológicos. Valendo-se de infraestrutura computacional capaz de captar, registrar, organizar e disponibilizar os dados das atividades envolvidas no setor, desde as atividades arqueológicas em grandes empreendimentos até a pesquisa científica.

conjunto de soluções

tecnológicas para

o gerenciamento

do grande volume de informações
Atualmente a plataforma é instrumento diário de gerenciamento e qualificação de informações, garantindo a rastreabilidade e a qualidade dos dados gerados por todo o processo, mas também abrindo novos caminhos para a pesquisa e análise de dados arqueológicos e paleontológicos.

A Plataforma Capivara conta hoje com uma equipe interdisciplinar para a sua manutenção e expansão, incluindo profissionais tanto da arqueologia quanto da computação. Como exemplo de solução desse conjunto está a Summa Arqueológica e que cumpre dois importantes papeis no Inapas. Um é a organização e disponibilização de camadas de informações de alta relevância para pesquisadores e o outro e a divulgação científica. Para atender essa demanda a Summa foi construída para ser visualmente atraente e disponibilizar em linguagem acessível

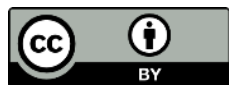


informações básicas, localização e amplo acesso aos registros fotográficos de sítios e vestígios arqueológicos registrados ao longo de toda a região.

\section{Clio Arqueológica: Como começou esse trabalho? O que levou ao desenho dessa plataforma?}

Eduardo Krempser: A demanda de um sistema de gerenciamento de informações arqueológicas não é, por si só, uma novidade. No Inapas e, em especial na Fumdham, por muito tempo se discutiu o tema e se adequaram sistemas para essa

o trabalho arqueológico, de forma geral, tem que estar disponível de maneira acessível à população finalidade. $\mathrm{O}$ desafio do projeto foi a implementação de uma ampla solução computacional que abrangesse o máximo de atividades arqueológicas possíveis. Depois de muita discussão com arqueólogos percebi e que o sistema deveria conectar atividades gerenciais e científicas e que também possuísse

flexibilidade para atender diferentes aspectos e profissionais a partir de uma ferramenta computacional com capacidade para a expansão da gestão, a integração e a análise de um grande volume de dados. É um caminho sem volta e esse sistema, assim como outros que virão no futuro são importante inovação técnico-científica. Isso gera uma profunda discussão interdisciplinar entre arqueologia e computação. 
A qualificação da informação armazenada, seu acesso por diferentes perfis e em tempo real e a sensibilidades das informações gerenciadas foram preocupações recorrentemente elencadas. Porém, a responsabilidade de disponibilização de informações e do conhecimento gerado para a sociedade também permeou o desenvolvimento da Plataforma, tendo-se em mente que o trabalho arqueológico, de forma geral, tem que estar disponível de maneira acessível à população.

Por tudo isso a Plataforma baseou-se na ampla experiência da Fumdham em atividades arqueológicas em diferentes aspectos para o desenvolvimento de uma plataforma computacional capaz de interagir desde a disponibilização de dados básicos até o registro minucioso de atividades de campo e laboratoriais.

\section{Clio Arqueológica: É um projeto bem amplo, até audacioso a nível de Brasil.}

Eduardo Krempser: Sim, é um projeto bastante audacioso, que tem muito a ser discutido, a ser divulgado e aprimorado. Mas esse trabalho vem de um processo de desenvolvimento bastante maduro, já responsável por gerenciar centenas de milhares de informações arqueológicas e disponibilizar soluções como a Summa Arqueológica para a sociedade, com mecanismos adaptáveis a novas demandas das atividades arqueológicas. Penso que tem um potencial de qualificação das informações e das atividades que é um grande exemplo de como a computação e novas tecnologias podem aprimorar o trabalho dentro da própria arqueologia.

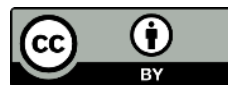


Clio Arqueológica: A divulgação científica, principalmente os periódicos, são qualificados através de sistemas informáticos através de modelos de banco de dados, indexadores e certificações digitais. Qual sua opinião sobre essas métricas?

Eduardo Krempser: A questão das métricas é um lado sensível na avaliação da qualidade de um periódico. Elas têm um impacto importante, pois tentam qualificar trabalhos científicos, que na maioria dos casos foram avaliados por pares. Isso pode ter impactos econômicos e sociais bastante profundos.

Nenhuma métrica pode ser interpretada destoante do cenário em que o artigo foi concebido
A análise dos dados, no caso de um periódico ou de um artigo, é sensível quando se remete apenas ao valor absoluto resultante. Nenhuma métrica pode ser interpretada destoante do cenário em que o artigo foi concebido. As métricas, a meu ver, de forma geral, são

indicadores criados com uma razão justa e bem intencionada. É necessário dar relevância aos trabalhos de cunho científicos e dar mais destaque aos que tenham uma maior repercussão e impacto. A grande questão é que, por vezes, essa é uma visão muito generalista sobre os trabalhos como um todo e ela pode ser falha quando esses trabalhos demandam de um público muito específico e restrito ou até ter relevância dependente do momento. 
Acredito que o perigo dessas métricas reside no fato de que pode desencadear uma linha tendenciosa de pensamento de trabalho. A questão é mais crítica quando vemos que o número, ou seja, o simples valor absoluto, pode criar um viés oposto ao que foi idealizado para aquela avaliação

\section{o simples valor} absoluto, pode criar um viés oposto ao
que foi idealizado do artigo, uma vez que correr atrás de uma pontuação não condiz com uma qualificação do trabalho em si. Publicar pensando no quanto se tem que alcançar numericamente, número de citações por

exemplo, é uma situação que deve ser reavaliada. Evidentemente não há uma resposta simples para as métricas, mas a discussão do que se espera com elas deve ser reaberta.

Clio Arqueológica: Se por um lado a divulgação e a disponibilidade de dados on-line é um benefício, há algum efeito secundário nesse mundo virtual, em relação as pesquisas científicas e sua divulgação, mais especificamente na arqueologia?

Eduardo Krempser: Acredito que um dos maiores benefícios da disponibilização de dados de forma on-line está na divulgação conjunta do conhecimento gerado, e que devem estar sempre associados. Penso que isso deve atingir o maior número de pessoas possíveis. Acho que é o que esperamos da divulgação da ciência. É essa divulgação e disponibilização que permitirá alavancar novos processos, novos 
conhecimentos e novas pesquisas. E por isso, além de um benefício claro, é também um processo irreversível.

\section{Clio Arqueológica: Sim, entendo. Mas há efeitos secundários?}

Eduardo Krempser: Sempre existem. E a questão da disponibilização em larga escala pode trazer efeitos secundários ou, ao menos, não esperados dessa ação. Alguns efeitos podem ser positivos, como a internalização de que a gerência desses dados tem que estar presente em todas as etapas do processo. Agora, é evidente que os pesquisadores têm que pensar de forma bastante cuidadosa nos efeitos negativos que isso pode acarretar e que, apesar de menores do que os benefícios, eles existem e devem ser minimizados.

\section{a divulgação de uma informação leva à \\ permanente responsabilidade sobre ela}

No momento em que vivemos, de uma crise na divulgação de informações, especialmente as informações pessoais, mas também de informações sensíveis, muitas vezes advindas de pesquisas científicas, temos que ter ainda mais cuidado. É impossível não mencionar a necessidade de reforçar a segurança da informação, a segurança na divulgação e o critério na análise das informações a serem divulgadas. Este trabalho envolve várias áreas do conhecimento, desde a análise de sensibilidade das informações até as 
questões computacionais de segurança em si. Além disso é necessário pensar como se espera que a informação será utilizada, para que possamos adequar os mecanismos que irão lidar com questões que vão desde o referenciamento das fontes até os momentos de disponibilização, sendo que esses pontos devem ser questionados continuamente. Isso porque a divulgação de uma informação leva à permanente responsabilidade sobre ela. Ou seja, não é apenas o processo de disponibilizar, mas o de se cercar das garantias necessárias de que os dados são qualificados.

Por fim, é preciso reforçar que o domínio das áreas de conhecimentos, seus contextos e a semântica de uma interpretação, não podem ser sobrepostos pela simples utilização de dados. Os mecanismos estatísticos e computacionais para a análise de dados não se desassociam do conhecimento das áreas em si.

\section{Clio Arqueológica: Como a Inteligência Artificial pode apoiar a pesquisa em Arqueologia?}

Eduardo Krempser: A inteligência artificial e mais especificamente a aprendizagem de máquina, pode apoiar diversas linhas de pesquisa em Arqueologia, ao passo que se vale da capacidade de processamento computacional e da busca de informações em grandes volumes de dados, incluindo a busca e o processamento de imagens, para indicar novas relações entre variáveis antes não exploradas. Ainda mais, pode atuar na geração de modelos que sistematizem 
conhecimentos antes vistos de forma mais subjetiva. Essas soluções podem abrir novas linhas de aprofundamento, sempre associada ao conhecimento especialista, sendo então corroboradas ou criticadas.

Clio Arqueológica: Por último, o que o Senhor recomendaria para os arqueólogos em termos de sistemas informático?

Eduardo Krempser: Consultem a Plataforma Capivara e nos ajudem a melhorála. Quanto mais sítios e mais dados, melhor. Ah, e por favor, não esqueça de disponibilizar o endereço eletrônico. ${ }^{5}$

Clio Arqueológica: Pode deixar, faremos com imenso prazer.

${ }^{5} \mathrm{http}: / /$ summa.fumdham.org.br 